\title{
Practice of Teaching and Construction of Hydraulic Engineering Specialty in Higher Vocational Colleges
}

\author{
Zhang Yufeng, Zhao Yanlin \\ company Yang Ling Vocational and Technical College, Yang Ling, Shaanxi, 712100, China
}

\begin{abstract}
Therefore, higher vocational colleges should pay attention to water conservancy engineering specialty and do well the training work of water conservancy engineering. At the same time, the teaching of production integration can not only make the students of water conservancy engineering master the knowledge of pre-settlement or measurement effectively, but also make them deal with common technical problems scientifically, thus improving the comprehensive ability of water conservancy engineering students.
\end{abstract}

Keywords: higher vocational college; water conservancy project; integrated teaching

\section{Introduction}

At present, the motive of higher vocational education is more and more clear, that is, to cultivate applied talents and improve the skills of higher vocational students, among which water conservancy engineering specialty has obvious practicality. Therefore, in teaching, we should carry out the teaching method of production integration, so that the teaching of water conservancy projects can be optimized, so as to improve students' practice and application skills while meeting the requirements of horizontal engineering specialty. In order to prepare for the future practice of water conservancy projects.

I. Current Situation Analysis of the Teaching of Hydraulic Engineering Specialty in Higher Vocational Colleges

https://doi.org/10.47852/bonviewCETR2020010235

This is an open access article published by the BON VIEW PUBLISHING PTE. under the Creative Commons Attributions License. 
(1) Lacking clear teaching objectives

From the point of view of the characteristics of higher vocational education, its teaching goal should be to train high-tech or skilled talents, so as to meet the needs ${ }^{[1]}$ related positions in various enterprises. Although higher vocational colleges gradually explore the relevant objectives of talent training, and gradually form a number of suitable for the school's talent objectives, but there are great deficiencies in the practice of teaching objectives. Taking the major of water conservancy engineering as an example, when teaching this major, we need to rely on practical teaching. However, some teachers are vague about the practical teaching objectives, do not clearly position them, neither arrange comprehensive practical training contents, nor lack of practical training links related to innovation and entrepreneurship, which not only affect the teaching of water conservancy projects. And can not evaluate the teaching objectives.In addition, the curriculum system also has a great impact on professional posts. If the curriculum system or curriculum standards can not be naturally integrated with professional posts, on the one hand, it will affect the employment of water conservancy students. On the other hand, it will reduce practical skills related to water conservancy projects. What's more, the current teaching content is not integrated with modern innovative science and technology, which makes the knowledge of water conservancy engineering students relatively narrow and unable to have innovative consciousness.

(2) Low integration of education and industry

The integration of production and teaching belongs to the practical teaching mode. It can not only make use of the practical resources of schools or enterprises, but also give play to the advantages of "double subjects ", enhance the comprehensive ability of water conservancy students, and make them realize" zero distance "employment. However, some schools do not apply science to the integration of industry and education, so that they are in a relatively low stage. For example, the total number of practical teaching bases is small, and some adopt the form of short-term contracts, and do not form a long-term mechanism. The integration of industry and education is affected. There are following reasons, which includes : First of all, the teaching conditions are relatively poor, resulting in the content of teaching materials or training practice projects can not be effectively carried out, some of the western countries now began to use electronic teaching materials and teaching plans, not only to make teaching more convenient network curriculum can make up for some traditional classroom shortcomings ${ }^{[2]}$ improve teaching effectiveness. However, some schools lack investment in teaching resources and can not let electronic teaching materials be used, which affects students' learning of water conservancy engineering knowledge.Secondly, it lacks the training center construction.Because the major of water conservancy engineering needs students to practice and make them understand all kinds of water conservancy materials, it is very important to build a simulation construction platform during this period.Through the establishment of practical training center, students can not only understand water conservancy equipment or materials, improve their cognitive level, but also exercise their operational skills of water conservancy projects and improve teaching effect. However, in teaching, 
teachers do not pay attention to the training center, which makes students lack the opportunity of model test and restricts their ability of water conservancy engineering.

\section{Analysis on the Way of Construction of Hydraulic Engineering Specialty Based on Integration of Production}

(1) Improving the Teaching Objectives System

In the new situation, the integration of industry and education will play a great role in the teaching of water conservancy projects, so we must perfect the teaching target system. First of all, vocational schools need to use vocational education group platform, so that schools and enterprises can achieve smooth.This can not only strengthen the communication with the relevant enterprises, understand their requirements for water conservancy talents, but also investigate the quantity of water conservancy talents in a certain area, and master the requirements of water conservancy talents' ability. In this way, it can not only adjust the course of water conservancy project, but also make the assessment standard related to professional ability, evaluate the students of water conservancy specialty effectively and improve the teaching effect.Second, the school should also take the cognitive law fusion as the precondition, effectively establishes the practice training or the practice ability standard. On the one hand, it can make students have a certain understanding ${ }^{[3]}$ practical training, carry out according to various standards, on the other hand, it can connect practical teaching and enterprise production with each other, and enhance students' practical skills of water conservancy. During this period, teachers should combine the theory of water conservancy engineering to realize the effective orientation of the curriculum and understand the specific market situation of their major. This can not only make the course suitable for water conservancy engineering specialty, but also grasp the development direction of water conservancy engineering and improve the effect of talent training. In addition, teachers should combine computer and practical teaching to strengthen practical courses.For example, the internal training base and the off-campus water conservancy project base are closely integrated, so that in teaching, the teaching resources of water conservancy projects are displayed first, so that the higher vocational students can perceive directly.And in practical training, through practical engineering to implement on-site teaching, it will enhance the practical ability of higher vocational students.

(2) Building a Practical Teaching Platform

The integration of industry and education began to become the main requirement of practical teaching in higher vocational education. On the one hand, higher vocational colleges carry out multidirectional exploration of practical teaching, mode of school leading and enterprise participation, on the other hand, relying on campus resources, they can use various ways to build practical platform of water conservancy projects. Strengthen innovative education, and then cultivate comprehensive skills of higher vocational students. In order to show the effectiveness of practical teaching in school, first of all, the school should update the current training room equipment or facilities, so that the basic functions of the software can be effectively upgraded.This can not only optimize the practical teaching process, 
but also enable students to strengthen the research on engineering projects with the help of practical platform, so as to effectively implement the innovative training plan and improve practical skills. Secondly, we should make use of enterprise resources to build the relevant training base of integration of industry and education scientifically.During this period, the model of integration of production and education should be implemented according to the principles of co-construction and co-management of schools and enterprises. It can not only set up the experimental platform of practical training inside and outside the school, but also make the main body of investment become diversified, and construct the training base in the form of cooperation, so as to meet the practical training needs of higher vocational students.Finally, the off-campus training platform should also be familiar with the new technology of the industry or enterprise, transform it into the practical teaching content of water conservancy projects, and let students perceive the real working environment.As a result, it can not only be familiar with the business process, but also realize the cultivation of professional ability, and then achieve the goal of "double subject" of school and enterprise, and realize the ${ }^{[4]}$ of cooperation and win-win.In addition, during the integration of industry and education, those enterprises with conditions should be encouraged to develop practical courses with schools, such as "certificate" courses, so that the vocational ability of higher vocational students can be enhanced.

(3) Strengthening the construction of teachers

The integration of industry and education can not be separated from the team of professional teachers.Therefore, we should effectively build a team of teachers, integrate industry experts and curriculum experts, and set up a curriculum development team. As a result, it can not only investigate the water conservancy engineering specialty scientifically, but also analyze the ${ }^{[5]}$ of each teaching task effectively, so as to perfect the curriculum system and make it develop gradually to the aspect of professional ability. First of all, we should set up a teaching management center. On the one hand, the management center can make the training documents, and carry out the training rules well, so that the teachers can master these rules comprehensively, on the other hand, the teachers can be encouraged to carry out the practical teaching tasks effectively.During this period, the teaching and research department should refer to the nature of practical teaching, scientific design practice teaching related links.This can not only specify the teaching contents or methods in detail, but also standardize the standards of practical training assessment, so as to encourage students to participate in various types of innovation competitions and enhance their innovative ability.Secondly, we should build the "doublequalified" team effectively.For example, combined with the characteristics or development trend of practical teaching, flexible methods are used to introduce water conservancy engineering teachers with certain enterprise background. At the same time, the school should encourage the professional teachers to exercise in the front line of the enterprise. This can not only be familiar with the production process of water conservancy projects, but also participate in scientific research or technology development. In 
addition, high-skilled or engineering managers should be introduced to become part-time teachers, and relatively flexible ways should be adopted to effectively arrange part-time teachers to ensure that they can guide students in practice.In this process, it is necessary to ensure that part-time teachers are longterm and effective, higher vocational students receive practical education.

\section{Conclusion}

The integration of industry and education should be a long-term and systematic process, so in the teaching of water conservancy engineering, it is necessary to consider the overall development trend of integration of industry and education and integrate it with vocational education. This can not only show the characteristics of practical teaching, but also enrich the content of practical training and innovative education, and improve the teaching effect.

\section{Acknowledgement}

This work was supported in part by Yang Ling Vocational and Technical College 2019 Humanities and Social Sciences Project"the compilation and Application of New loose-leaf Teaching Materials-take the course of "introduction to Water Conservancy Project “,No.GJ19005.

\section{References}

[1] Wen Aicun. Construction and Practice of Teaching Team of Water Conservancy Engineering Specialty Based on Integration of Industry and Education in J/OL]. Vocational Colleges China Building Materials Technology :1-2

[2] Li Xuezhuan, Zhou Ru. A Preliminary Study on Optimization of Higher Vocational Water Conservancy Specialty Based on the Integration of J]. and Education Journal of Changjiang Engineering Vocational and Technical College,2020,37(01):22-23+71.

[3] Liu Qigou.Based on Supply-side Reform of Fujian Water Conservancy Vocational Education. [J] Based on Integration of Industry and Education Journal of Changjiang Engineering Vocational and Technical College,2019,36(01):32-35.

[4] Zhao Jingfen. Research on the Training System of Water Conservancy Talents in Higher Vocational Education Based on the Integration of Industry and Education — Taking Liaoning Water Conservancy Vocational College as an example [J].] A Liaoning higher Vocational Journal ,2016,18(09):5-7.

[5] Peng Xiaolan. Based on the "integration of production and learning, education in reality" professional construction program [J].]; and China's out-of-school education ,2014(S2):170-171. 